ONE HUNDRED AND SIXTY-FOURTH SCIENTIFIC MEETING SIXTY-NINTH OF THE SCOTTISH GROUP

ROWETT RESEARCH INSTITUTE, BUCKSBURN, ABERDEEN

II APRIL 1964

\title{
NUTRITION OF MICRO-ORGANISMS
}

\author{
Chairman: Magnus Pyke, Esq., BSc, PHD, FRIC, The Distillers Co. Ltd, \\ Menstrie, Clackmannanshire
}

\section{Nutritional and environmental factors affecting the endogenous metabolism of bacteria}

\section{By E. A. Dawes, Department of Biochemistry, University of Hull}

Endogenous metabolism may conveniently be defined as the total metabolic reactions which occur within the living cell when it is held in the absence of compounds or elements which serve specifically as exogenous substrates. However, it must be recognized that the reactions characteristic of endogenous metabolism may continue in the presence of exogenous substrates (Dawes \& Ribbons, I962a). Further, since the metabolism of exogenous substrates is usually effected after they have been taken into the cell, in the final analysis the distinction between the metabolism of endogenous and exogenous substrates may become largely a matter of semantics, although the possibilities of compartmentation within the cell must not be overlooked (Furano \& Green, 1963; Dawes \& Ribbons, 1964).

The endogenous metabolism of micro-organisms is necessarily related to their chemical composition and, as the cellular content of certain potential endogenous substrates is known to vary considerably with cultural conditions (see for example, Stephenson \& Whetham, r922; Dagley \& Dawes, r949; Dagley \& Johnson, 1953; Macrae \& Wilkinson, I $958 a$; Stanier, Doudoroff, Kunisawa \& Contopoulou, I 959), corresponding variations of endogenous metabolic activities might be expected to occur. Herbert ( $196 \mathrm{I}$ ) has already emphasized the futility of reporting the chemical composition of a micro-organism without at the same time specifying the environmental conditions that produced it; this stricture is equally apposite when referring to endogenous metabolism.

The existence of an endogenous metabolism does not, of course, necessarily imply the occurrence of specialized reserves of either carbon or energy within the cell, and it may well be that in the absence of nutrients essential cellular materials are degraded. There is now evidence to suggest that this is so with Pseudomonas aeruginosa, an organism which, when grown in a glucose-ammonium salt medium, does not possess reserves of either carbohydrate or lipid. Under conditions of starvation ribonucleic acid (RNA) and protein are degraded by this organism (Campbell, Gronlund \& Duncan, I963; Gronlund \& Campbell, I961, I963).

A consideration of the possible substrates for endogenous metabolism immediately focuses attention on energy storage compounds, of which there are two main classes, namely polysaccharides and lipids (including poly- $\beta$-hydroxybutyric acid, which is found only in micro-organisms). Additionally polyphosphate may serve this purpose, 
although doubt has now been expressed (Harold \& Sylvan, 1963). These compounds all occur in widely varying amounts depending upon the particular species and the environmental conditions for growth. During the past few years it has become apparent that there are many other cellular constituents which can serve as substrates for endogenous metabolism. These include RNA and protein, which are both also subjected to turnover, and free amino acid and peptide pools, i.e. all compounds which would normally be regarded as essential rather than reserve or storage materials, a fact which emphasizes that the basal or 'working' substance of the cell can be drawn upon for endogenous metabolism.

In the past it has not, perhaps, been adequately recognized that the bacterial cell content of such basal components as nucleic acids and protein can undergo marked variation. Herbert ( $196 \mathrm{I}$ ) has recorded a sixteenfold variation in the RNA content of Bacillus anthracis under different conditions of growth, and also cites data to illustrate the considerable variations between different bacterial species. Appreciable, though less extreme, changes in DNA content may also be found (two- to three-fold), and though protein content varies the least, up to twofold changes may be noted. The rate of growth of the organism appears to be a very important factor. Schaechter, Maaløe \& Kjeldgaard (1958) showed that over a wide range of growth rates the rate of protein synthesis in Salmonella typhimurium is roughly proportional to the RNA content of the cells and, by extrapolation to zero growth rate, Ecker \& Schaechter (1963) deduced that non-growing cells contain virtually no ribosomes. The correlation between bacterial cell size and the rate of growth, being now well established, does not warrant further discussion here, and attention may also be drawn to the comprehensive review by Neidhardt (1963) on the effect of environment on the composition of bacterial cells.

The deposition of storage materials in micro-organisms appears, in general, to be associated with conditions under which the cells have available the necessary building blocks for synthesis of the reserve and when the nitrogen source in the medium is either exhausted or becomes unavailable for growth purposes. Deposition of reserve materials can therefore be dissociated from the processes of growth.

Striking examples of the effect of chemical environment during growth on the metabolic activities of bacterial cells are to be found with those organisms which are able to synthesize alternative reserve materials. Two cases may be cited, Escherichia coli and Rhodospirillum rubrum. Dagley \& Johnson (1953) demonstrated that growth of E. coli on acetate-ammonium salt medium stimulated lipid synthesis and decreased polysaccharide production, whereas growth on glucose had the opposite effect. Endogenous metabolism was not studied, however.

The photosynthetic organism $R$. rubrum is able to store more than one polymer as a reserve material, and the polymer that is deposited within the cells is determined solely by the chemical nature of the carbon substrate supplied (Doudoroff \& Stanier, 1959). Those compounds which are converted to acetate without the intermediate formation of pyruvate or phosphoenolpyruvate yield poly- $\beta$-hydroxybutyrate, whereas those yielding the $3-\mathrm{C}$ compound produce glycogen. Thus acetate and butyrate result in the deposition of poly- $\beta$-hydroxybutyrate whereas carbon 
dioxide, succinate, malate and propionate are photoassimilated principally to a glycogen-like polysaccharide. On subsequent starvation, therefore, the endogenous metabolic activities reflect the particular polymer which is undergoing degradation.

The ability to store poly- $\beta$-hydroxybutyrate is widely distributed among Bacillus species and Macrae \& Wilkinson (1958a,b) have studied the effect of various cultural conditions on the synthesis of the polymer in Bacillus megaterium. They found that when the glucose concentration in the medium was raised more of the polymer was synthesized; exhaustion of the nitrogen source in the medium in the presence of excess carbon and energy source permitted deposition of about four times the amount of poly- $\beta$-hydroxybutyrate as when glucose limited growth. When the cells were starved the polymer was metabolized and some correlation was evident between their poly- $\beta$-hydroxybutyrate content and the endogenous respiration, although some other material (not polysaccharide) was clearly being degraded. Cells with a higher polymer content were better able to withstand death and autolysis.

The 'volutin' granules of many bacteria have been identified as deposits of inorganic polyphosphate and the possible role of this material as an energy reserve was appreciated with the discovery in Escherichia coli of the enzyme polyphosphate kinase (Kornberg, Kornberg \& Sims, 1956; Kornberg, 1957). This enzyme catalyses the transfer of the terminal phosphate of ATP to polyphosphate and it was envisaged that polyphosphate accumulation results from ATP synthesis in excess of cellular requirements for biosynthetic or maintenance purposes, the excess ATP being utilized for polyphosphate synthesis. The reaction could possibly fulfil two purposes (a) the storage of high-energy phosphate or (b) the dissipation of ATP with regeneration of ADP and inorganic phosphate. However, recent work with Aerobacter aerogenes (Harold, I963a,b; Harold \& Sylvan, 1963), on the factors which result in accumulation and utilization of polyphosphate, has shown that polyphosphate synthesis accounts for but a small fraction of the available ATP, and this has led Harold to the view that polyphosphate is not of significance for energy metabolism but is concerned with phosphorus balance in the cell, i.e. to be regarded as a reserve of phosphorus rather than of energy. This is an area of intensive research activity at present and the situation will undoubtedly be much clarified in the near future.

The findings of Harold $\left(\mathrm{I}_{96} 6_{3} a\right.$ ) and Harold \& Sylvan ( 1963$)$ revealed that, when growth of $A$. aerogenes ceases as the result of a nutritional deficiency in media of low inorganic phosphate content, large amounts of polyphosphate accumulate within the cells. A competition for intracellular phosphorus occurs between nucleic acid and polyphosphate such that polyphosphate accumulates only after nucleic acid synthesis has ceased. Resumption of nucleic acid synthesis causes rapid degradation of polyphosphate with transfer of the phosphorus to RNA. In media of high phosphate content, however, polyphosphate accumulation is induced only by sulphur starvation, and oxidized glutathione, or a closely related compound, was identified as an intracellular inhibitor of polyphosphate accumulation. These workers believe that the primary effect of glutathione plus phosphate is on the stimulation of polyphosphate degradation. The influence of the nutritional state of the cells on polyphosphate accumulation is thus apparent. 
Sarcina lutea was the first organism shown to utilize its free amino acid and peptide pool as a substrate for endogenous metabolism (Dawes \& Holms, I958); subsequently other organisms, including Nocardia rugosa (Bardi \& Boretti, I958) and Staphylococcus aureus (Ramsey, I962; D. Ivler, personal communication) have been found to do likewise. When S. lutea, harvested from the stationary phase in peptone medium, is subjected to starvation for several hours no detectable change in the carbohydrate or lipid content of the cells occurs, but the free amino acid pool is diminished by approximately one-half, an equivalent amount of ammonia is released into the suspending fluid, and the endogenous respiration rate falls to a negligible value. Only certain amino acids contribute in this way to the endogenous respiration, and during starvation the pool does not appear to be replenished from protein reserves. No significant change in the ultracentrifugal pattern of cell extracts was detected after starvation for $5 \mathrm{~h}$, although in much extended periods of up to $46 \mathrm{~h}$ (I. G. Burleigh \& E. A. Dawes, unpublished observations) changes in ribonucleoprotein content have been recorded. Hoare (1955) demonstrated that $S$. lutea absorbs a wide variety of free amino acids in varying proportions, depending on the medium in which it is growing. As some of the amino acids affected in this way are now known to be associated with endogenous respiration, variation in this property would be expected according to the composition of the growth medium employed, emphasizing again the importance of environment during growth.

Burleigh (unpublished observations) has now investigated the effect of the phase of growth on the endogenous metabolism and intracellular concentrations of potential endogenous substrates. The endogenous $Q_{0_{2}}$ fell throughout the growth cycle and this decrease continued in the stationary phase. It was paralleled by a decrease in the free amino acids of the cell; protein and orcinol-reactive material also decreased during exponential growth, but levelled off at the onset of the stationary phase.

When $S$. lutea is grown in glucose-peptone medium quantities of a utilizable carbohydrate, averaging about $12 \%$ of the dry weight, are deposited in the cells and can subsequently be degraded as a secondary endogenous substrate (Ribbons \& Dawes, 1963; Burleigh, Dawes \& Ribbons, 1963). This carbohydrate reserve is a non-reducing polyglucose, soluble in hot water, and possession of it neither spares the utilization of the free amino acid pool, nor inhibits the release of ammonia from the cells. It is not responsible for a significant contribution to the observed high endogenous $Q_{0_{2}}$ values, although the possibility that it might confer an increased capacity for survival remains to be investigated.

The effect of previous nutritional history on the survival of stationary phase $A$. aerogenes in $\mathrm{NaCl}$-phosphate buffer solutions has been extensively investigated by Strange, Dark \& Ness (I96I). Cells were harvested from aerated cultures of defined mannitol-ammonium salt, tryptic meat broth, and tryptone-glucose media and held at $22^{\circ}$ under nitrogen or at $37^{\circ}$ with aeration. Cellular composition differed according to the growth medium and cells from the complex media survived better than did those from the defined medium. Tryptone glucose-grown cells had a high carbohydrate content (approx. $2 \mathrm{I} \%$ of the dry weight) and glycogen was depleted during the initial $25 \mathrm{~h}$ of incubation, with a small decrease in protein and no change in 
RNA content. After glycogen had been consumed, further protein degradation occurred and, to a smaller extent, degradation of RNA commenced. Cells from tryptic meat broth and the defined medium, which contained much less carbohydrate $(4-6 \%)$, degraded their protein and RNA with little change in carbohydrate content. These workers were able to demonstrate that glycogen is an important endogenous reserve in $A$. aerogenes and its presence in the cell favours survival. When glygocen is not available, the residual (structural) carbohydrate is not utilized, but degradation of protein and RNA occurs. The extent of RNA degradation depended on the source of the cells, once again underlining the importance of the nutritional environment during growth (Strange et al. I96r).

Environmental conditions also play an important role in determining the endogenous metabolism of E. coli. Glycogen is a primary substrate for endogenous metabolism and only when it is exhausted does net degradation of protein occur (Ribbons \& Dawes, 1963), although turnover of protein commences immediately the cells are starved (Ribbons \& Dawes, unpublished observations). The glycogen content of $E$. coli varies considerably with growth phase, growth medium and conditions of culture. High glycogen contents and endogenous $Q_{0_{2}}$ values are observed soon after the onset of the stationary phase in unaerated ammonium salt media containing glucose. Though aeration does not appreciably alter the pattern, lower glycogen contents are usually observed with cells from such media.

Replacement of ammonium salt in glucose medium by tryptone leads to a suppression of glycogen deposition. Tryptone-grown cells and cells grown in succinateammonium salt do not contain any glycogen, and on starvation net degradation of protein occurs immediately with release of ammonia. Degradation of RNA was found to commence as soon as the cells were starved and irrespective of whether they contained glycogen. Unlike $S$. lutea, the free amino acid pool of $E$. coli is not depleted on starvation.

The importance of the phase of growth in relation to the endogenous metabolism of $E$. coli is illustrated by endogenous respiration rates obtained over a period of growth of only 2-3 $\mathrm{h}$, and which ranged from $Q_{0_{2}}$ values of 10 to values of 40 . These results with batch cultures reveal a close correlation between the endogenous $Q_{0_{2}}$ value and the glycogen content of the cells and, furthermore, that glycogen content is a function of the nutritional and cultural conditions

\section{Application of continuous culture techniques}

In batch culture, throughout the period of growth and well into the stationary phase, the environment is undergoing continual change with respect to nutrient concentrations and often also with respect to aeration and $\mathrm{pH}$. If, therefore, one wishes to study particular aspects of endogenous metabolism uncomplicated by these factors the necessity for controlling the environment becomes paramount and recourse must be had to continuous culture techniques. By such methods the experimenter can control all these variables, and also the rate of growth of the culture by feeding a specific nutrient at a concentration which limits growth. Thus not only can cells be grown in an unchanging environment under conditions of carbon or nitrogen 
limitation, but also with limited phosphorus, sulphur or metallic ions; growth is thereby secured under steady-state conditions. It will be apparent that the technique offers a powerful weapon for the investigation of endogenous metabolism, and some of the results which have a bearing on this topic will now be reviewed.

Holme (1957, 1958) studied glycogen formation during continuous cultivation of E. coli $\mathrm{B}$ and found that, in nitrogen-limiting medium, the rate of glycogen synthesis increased when the growth rate decreased, and the glycogen content of the cells could be controlled to values between about $2 \cdot 3$ and $20 \%$ of the bacterial dry weight. Endogenous respiration rates were not recorded, however. The glycogen content was higher with glucose than with lactate as the carbon and energy source. Similar findings have been recorded by Herbert (1958) for Torula utilis in nitrogenlimited media; when growth was limited by glucose, however, variation of growth rate had little effect on the rates of either endogenous respiration or the oxidation of glucose, whereas fermentative activity towards glucose was virtually abolished at low rates of growth.

A decrease in the yield of cells in continuous culture has been observed at low growth rates with certain organisms in glucose or glycerol-ammonium salt media, where the carbon source limits growth rate (Herbert, 1958). An explanation for this observation can be offered in terms of a constant endogenous metabolism which, at low growth rates, becomes proportionally more important compared with the anabolic metabolism, with a consequent decrease in cell yield. Thus the expression for the exponential growth rate $\mu, d x / d t=\mu x$, must be modified by a constant term $k$ representing the endogenous metabolism and becomes $d x / d t=(\mu-k) x$, where $x$ is the concentration of bacteria (mg dry weight $/ \mathrm{ml}$ ) and $t$ is the time. By measuring the rates of oxygen consumption and carbon dioxide evolution of $A$. aerogenes at different growth rates in glycerol-limiting ammonium salt medium, more direct evidence for the role of the endogenous metabolism was obtained (Herbert, 1958). $Q_{0_{2}}$ and $Q_{\mathrm{CO}_{2}}$ values were found to be a linear function of the growth rate and extrapolation to zero rate of growth yielded finite values for both these parameters, corresponding to the endogenous respiration rates. Carbon balance studies confirmed that a lower proportion of the substrate carbon is converted into cell carbon and a higher proportion into $\mathrm{CO}_{2}$ at low rates of growth.

Munro \& Wilkinson (quoted by Wilkinson, r 963 ) have used continuous cultivation to examine poly- $\beta$-hydroxybutyrate production in nitrogen-deficient cultures of Bacillus megaterium. They found that appreciable amounts of the polymer were produced at all growth rates although the rate of synthesis was higher at faster rates of growth. Data for endogenous metabolism were not reported in these experiments.

Other experiments with $A$. aerogenes in continuous culture have been reported by Postgate \& Hunter ( 1962 ) who studied the survival in saline-tris buffer of cells grown in an ammonium salt medium containing limiting amounts of glycerol. Organisms grown under these carbon-limiting conditions contained little polysaccharide and, on starvation, their RNA was metabolized first, the ribose being substantially oxidized, adenine and cytosine (but not guanine) deaminated and released, and inorganic phosphate released from the cells. The observed fall in endogenous $Q_{0_{2}}$ 
value could probably be accounted for by ribose oxidation. Protein was metabolized subsequently, at such a rate that the free amino acid pool remained unchanged for several hours (cf. E. coli (Dawes \& Ribbons, I962b)). Thus, after growth under these particular conditions, RNA is the preferentially utilized endogenous substrate.

The importance of $\mathrm{Mg}^{2}+$ ions for the stability of bacterial RNA is now well recognized (Bowen, Dagley \& Sykes, I959; Wade, 196r), although the full significance of its role in endogenous metabolism remains to be elucidated. The far-reaching effects of $\mathrm{Mg}^{2}+$ deficiency are amply illustrated by the recent work of Tempest \& Sykes (1964) with Pseudomonas fluorescens growing in $\mathrm{Mg}^{2+}$-limited continuous culture. The oxidation of citrate, succinate, acetate and glucose was stimulated by the addition of $\mathrm{Mg}^{2+}$ and the uptake of glucose was dependent on it. RNA synthesis was also stimulated by $\mathrm{Mg}^{2+}$, although the RNA produced was subsequently readily lost from the cells. It seems possible that loss of $\mathrm{Mg}^{2}+$ from bacterial cells during starvation could affect the activity of enzyme systems which might well be concerned with the processes of turnover and the provision of energy of maintenance.

In conclusion, it will be apparent from this survey that nutritional and physicochemical factors of the enviroriment can exert profound effects on the endogenous metabolism of micro-organisms. Although certain aspects of this problem have been studied, many others still await investigation-a comprehensive analysis of the effect of starvation on various constitutive enzymes, for instance - and the application of continuous cultivation methods should greatly facilitate the experimentalist's task.

\section{REFERENCES}

Bardi, U. \& Boretti, G. (1958). G. Microbiol. 6, 9r.

Bowen, T. J., Dagley, S. \& Sykes, J. (1959). Biochem. F. 72, 4 I9.

Burleigh, I. G., Dawes, E. A. \& Ribbons, D. W. (1963). Biochem. F. 88, 3oP.

Campbell, J. J. R., Gronlund, A. F. \& Duncan, M. G. (1963). Ann. N.Y. Acad. Sci. ro2, 669.

Dagley, S. \& Dawes, E. A. (1949). Biochem. F. 45, 33 I.

Dagley, S. \& Johnson, A. R. (1953). Biochim. biophys. Acta, II, 158.

Dawes, E. A. \& Holms, W. H. (1958). Biochim. biophys. Acta, 30, 278.

Dawes, E. A. \& Ribbons, D. W. (1962a). Annu. Rev. Microbiol. 16, 24 I.

Dawes, E. A. \& Ribbons, D. W. (1962b). Biochem. F. 82, 49 P.

Dawes, E. A. \& Ribbons, D. W. (1964). Bact. Rev. 28, 126.

Doudoroff, M. \& Stanier, R. Y. (1959). Nature, Lond., 183, I440.

Ecker, R. E. \& Schaechter, M. (1963). Ann. N.Y. Acad. Sci. 102, 549.

Furano, A. V. \& Green, J. P. (1963). Nature, Lond., 199, 380.

Gronlund, A. F. \& Campbell, J. J. R. (I96I). F. Bact. 81, 72 I.

Gronlund, A. F. \& Campbell, J. J. R. (1963). F. Bact. 86, $5^{8}$.

Harold, F. M. (1963a). F. Bact. 86, 216.

Harold, F. M. $(1963 b)$. 7. Bact. 86, 885 .

Harold, F. M. \& Sylvan, S. (1963). F. Bact. 86, 222.

Herbert, D. (1958). Symp. int. Congr. Microbiol. vi. Stockholm, p. 381.

Herbert, D. (1961). Symp. Soc. gen. Microbiol. I1, 391.

Hoare, D. S. (1955). F. gen. Microbiol. 12, 534.

Holme, T. (1957). Acto chem. scand. II, 763 .

Holme, T. (1958). In Continuous Cultivation of Micro-organisms: a Symposium, p. 67. Prague: Czechoslovak Academy of Sciences.

Kornberg, S. R. (1957). Biochim. biophys. Acta, 26, 294.

Kornberg, A., Kornberg, S. R. \& Sims, E. S. (1956). Biochim. biophys. Acta, 20, 215.

Macrae, R. M. \& Wilkinson, J. F. (1958a). Proc. R. phys. Soc. Edinb. 27, 73.

Macrae, R. M. \& Wilkinson, J. F. (1958b). F. gen. Microbiol, r9, 2 10.

Neidhardt, F. C. (1963). Annu. Rev. Microbiol. 17, 61.

Postgate, J. R. \& Hunter, J. R. (I962). F. gen. Microbiol. 29, 233. 
Ramsey, H. H. (1962). F. Bact. 83, 507.

Ribbons, D. W. \& Dawes, E. A. (1963). Ann. N.Y. Acad. Sci. ro2, 564.

Schaechter, M., Maaløe, O. \& Kjeldgaard, N. O. (1958). F. gen. Microbiol. r9, 592.

Stanier, R. Y., Doudoroff, M., Kunisawa, R. \& Contopoulou, R. (1959). Proc. nat. Acad. Sci., Wash., $45,1246$.

Stephenson, M. \& Whetham, D. (1922). Proc. roy. Soc. B, 93, 262.

Strange, R. E., Dark, F. A. \& Ness, A. G. (196r). F. gen. Microbiol. 25, 6 I.

Tempest, D. W. \& Sykes, J. (1964). 2nd int. Fermentation Symp., London. Abstract B8.

Wade, H. E. (1961). Biochem. F. 78, 457.

Wilkinson, J. F. (1963). $\mathcal{F}$. gen. Microbiol. 32, I 7 I.

\section{The relationship between the composition of the environment and the control of biosynthesis in bacteria}

\section{By B. A. Fry, Department of Microbiology, University of Sheffield}

In addition to defining the requirements for growth, investigations of the nutrition of micro-organisms have led directly to a greater understanding of the part played by environmental compounds in the functioning and the control of microbial metabolism. At first, attention was focused on the role of growth factors of the vitamin B group (e.g. growth factor replacement technique; Lampen, Roepke \& Jones, I946), routes of biosynthesis (e.g. tryptophan; Snell, r943), the mode of action of growth factor analogues (e.g. sulphanilamide; Kohn, 1943) and the total activity, and hence the amounts, of various enzymes in bacteria grown in different media. In some instances, enzyme formation was dependent on the presence of the specific substrate (or a closely related analogue) in the medium (inducible enzymes and inducers) whereas the formation of other enzymes (e.g. tryptophanase, threonine deaminase) was markedly reduced if the medium contained glucose (Epps \& Gale, 1942). In general, prototrophic bacteria do not excrete appreciable quantities of amino acids, purines, and pyrimidines into the medium. On the other hand, these organisms will preferentially utilize exogenous supplies of these compounds and, in some instances, endogenous synthesis then ceases (Abelson, 1954; Roberts, Cowie, Abelson, Bolton \& Britten, I 955). Information of this type, together with the results of detailed studies of the routes of biosynthesis of amino acids and other substances led to the conclusion that two types of mechanism were operative in the regulation of microbial metabolism. In the first type, a substance other than the substrate can control the activity of an existing enzyme in the cell. In the second, the synthesis of enzymes (and other proteins) is directly controlled by substances such as the substrate (inducible enzymes) or the end-product* of a biosynthetic sequence (repressible enzymes). Since many examples are now known (Tables I and 2) in which the products 'loop back' and affect the activity and synthesis of various enzymes concerned in their synthesis, such regulatory mechanisms have been termed feedback control mechanisms. Where the synthesis of an enzyme or protein is regulated, the mechanism is termed repression: where the activity of an enzyme is controlled, the mechanism is termed feedback inhibition.

\footnotetext{
*'Throughout this paper, the term 'end-product' means an amino acid, a pyrimidine or purine nucleotide or, with the glyoxylate cycle, a $\mathrm{C}_{4}$ or $\mathrm{C}_{3}$ acid: in other words it is the terminal product of a biosynthetic sequence of reactions.
} 